\title{
Changing prevalence and treatment of depression among older people over two decades
}

Antony Arthur, George M. Savva, Linda E. Barnes, Ayda Borjian-Boroojeny, Tom Dening, Carol Jagger, Fiona E. Matthews, Louise Robinson, Carol Brayne and the Cognitive Function and Ageing Studies Collaboration*

Depression is a leading cause of disability, with older people particularly susceptible to poor outcomes.

\section{Aims \\ To investigate whether the prevalence of depression and anti- depressant use have changed across two decades in older people.}

\section{Method}

The Cognitive Function and Ageing Studies (CFAS I and CFAS II) are two English population-based cohort studies of older people aged $\geq 65$ years, with baseline measurements for each cohort conducted two decades apart (between 1990 and 1993 and between 2008 and 2011). Depression was assessed by the Geriatric Mental State examination and diagnosed with the Automated Geriatric Examination for Computer-Assisted Taxonomy algorithm.

\section{Results}

In CFAS I, 7635 people aged $\geq 65$ years were interviewed, of whom 1457 were diagnostically assessed. In CFAS II, 7762 people were interviewed and diagnostically assessed. Age-standardised depression prevalence in CFAS II was 6.8\% (95\% Cl 6.3-7.5\%), representing a non-significant decline from CFASI (risk ratio 0.82 , $95 \% \mathrm{Cl} 0.64-1.07, P=0.14)$. At the time of CFAS II, $10.7 \%$ of the

\section{Background}

population (95\% Cl 10.0-11.5\%) were taking antidepressant medication, more than twice that of CFASI (risk ratio $2.79,95 \% \mathrm{Cl}$ 1.96-3.97, $P<0.0001)$. Among care home residents, depression prevalence was unchanged, but the use of antidepressants increased from $7.4 \%$ (95\% Cl 3.8-13.8\%) to $29.2 \%$ (95\% Cl 22.6-36.7\%).

\section{Conclusions}

A substantial increase in the proportion of the population reporting taking antidepressant medication is seen across two decades for people aged $\geq 65$ years. However there was no evidence for a change in age-specific prevalence of depression.

\section{Declaration of interest}

None.

\section{Keywords}

Depressive disorders; antidepressants; epidemiology; older people; primary care.

\section{Copyright and usage}

(c) The Royal College of Psychiatrists 2019. This is an Open Access article, distributed under the terms of the Creative Commons Attribution licence (http://creativecommons.org/licenses/by/4.0/), which permits unrestricted re-use, distribution, and reproduction in any medium, provided the original work is properly cited.

in England among people aged $\geq 65$ years has changed over two decades, between 1991 and 2011

\section{Method} to diagnose. ${ }^{2}$ Estimates of prevalence of major depression in those aged $\geq 75$ years range from 4.6 to $9.3 \%,{ }^{3}$ but sampling and measurement differences in these population-based studies make it difficult to determine whether these differences are real or artefactual. Evidence from studies across all age groups suggest that prevalence of major depressive disorder declines in later life, ${ }^{4,5}$ although the reverse may be the case for the presence of clinically significant depressive symptoms. ${ }^{6}$ Since the introduction of selective serotonin reuptake inhibitors in the late 1980s, there has been an increase in antidepressant prescriptions issued. ${ }^{7}$ Prescriptions dispensed for antidepressants increased more than threefold in England between 1991 and 2009, ${ }^{8}$ reflecting a trend observed in other Western countries. ${ }^{9,10}$ Establishing whether there are temporal changes in prevalence of depression among older people is a major challenge, requiring large studies undertaken at two or more points with sufficient time lapse, using the same sampling methods, geographical areas, interviewing approaches and diagnostic criteria. Against a backdrop of greater life expectancy and improved health in later life, the Cognitive Function and Ageing Studies (CFAS I and CFAS II (http://www.cfas.ac.uk)) provide a unique opportunity to test whether the prevalence of depression

* Members of the Cognitive Function and Ageing Studies (CFAS) Collaboration are listed in the Acknowledgements. 
geographical area, with equal proportions aged 65-74 years and aged $\geq 75$ years. Participants were initially approached via a letter from their registered general practice. This was followed by a visit from a study interviewer, who undertook the interview if the individual provided written informed consent. For individuals considered not to have mental capacity, as defined by the UK Mental Capacity Act, a request was made to interview an informant, typically a close relative.

The interviews were conducted face to face, by a trained study interviewer in the usual place of residence of the participant. The interviewer captured participant responses on a laptop computer. In CFAS I, baseline (screening) interviews contained questions about sociodemographic characteristics, perceived health, activities of daily living and use of health and social care services. Participants (and/or their informant) were asked about all medications they were currently being prescribed by their doctor as well as over-the-counter medications and supplements. Drug name, dose and frequency were recorded for all medications. At the assessment interview the Geriatric Mental State examination was undertaken. This is a standardised interview for ascertainment of the presence or absence of mental health disorders in older age. In CFAS II, one interview was conducted, which contained both the screening and assessment components. Further details of the approach and interview content have been previously published. ${ }^{11,12}$

CFAS I and CFAS II used the same Automated Geriatric Examination for Computer-Assisted Taxonomy algorithmic (AGECAT) approach ${ }^{13}$ to diagnose dementia, depression and other mental health disorders among participants in the two cohort studies. The presence or absence of depressive symptoms are used to categorise individuals into six levels of depression severity, which can then be collapsed into three groups: no symptoms (level d0), subclinical depression (levels d1 and d2) and case-level depression (levels d3-d5). Subclinical depression is characterised by minor mood symptoms and some non-specific symptoms (e.g. loss of energy, interest or enjoyment). Case-level depression comprises neurotic and psychotic subtypes, with attempts of suicide taking the diagnostic level to $\mathrm{d} 4$ or above. For those with more than one diagnosis, the AGECAT algorithm determines a primary diagnosis. Analysis presented here is restricted to those with a primary diagnosis of case-level depression (neurotic or psychotic). Patients were considered to be receiving antidepressants if they reported use of medications categorised within the British National Formulary (antidepressant sections 4.3.1-4.3.4). ${ }^{14}$

\section{Analysis}

All analyses were undertaken using weights, to adjust for (i) oversampling of those aged $\geq 75$ years and (ii) non-response using age, gender and deprivation status based on Townsend deprivation scores ${ }^{15}$ linked to postcode (CFAS I and II). Weights also adjusted for selection for assessment interview (CFAS I only). To account for changes in population structures, prevalence estimates from both CFAS I and CFAS II were calculated by standardising to the 2011 UK population age and gender distribution.

To investigate whether sociodemographic factors (age, gender, care home residence, centre, Townsend deprivation quartile) were associated with study diagnosis of case-level depression or being prescribed antidepressant medication, we used binomial regression models with a log link for each cohort to estimate risk ratios adjusted for each of the other sociodemographic factors. To test for a cohort effect, we used the same covariates for both cohorts combined. We additionally included interaction terms between each sociodemographic variable and cohort to estimate whether the relationship between sociodemographics and depression diagnosis or antidepressant had changed between the two cohorts.

\section{Ethics approval}

The authors assert that all procedures contributing to this work comply with the ethical standards of the relevant national and institutional committees on human experimentation and with the Helsinki Declaration of 1975, as revised in 2008. All procedures involving human subjects/patients were approved by local and multi-centre ethics committees (CFAS I: MREC99/5/22. 05/MRE05/37; CFAS II: 07/MRE05/48).

\section{Data availability}

The data sets analysed during this study are available upon reasonable request from the CFAS team (http://www.cfas.ac.uk/cfas-i/ data/).

\section{Results}

In CFAS I, 9345 individuals were eligible and approached to take part in the baseline screening interview in Cambridgeshire, Newcastle and Nottingham, of whom 7635 participated (response $81.7 \%$ ) and 1457 undertook the assessment interview. In CFAS II, of the 14228 individuals eligible to take part and approached, $7762(54.6 \%)$ were interviewed. Details of the change in response between the two cohorts have been previously reported. ${ }^{11}$ Supplementary Table 1 (available at https://doi.org/10.1192/bjp. 2019.193) describes the samples from each cohort and the numbers included in analyses.

The estimated prevalence of depression among people aged $\geq 65$ years in CFAS I was 7.9\% (95\% CI 6.3-9.9\%) and 6.8\% (95\% CI 6.3$7.5 \%$ ) in CFAS II (Table 1), a non-significant decline of around $20 \%$ in prevalence in the intervening two decades (adjusted risk ratio CFAS II versus CFAS I $0.82,95 \%$ CI $0.64-1.07, P=0.14$ ). The prevalence of depression was higher among women than men at both time points. There was no evidence of changes in the pattern of prevalence across age groups. The proportion of people aged $\geq 65$ years living in care homes has declined over the period between the two studies, ${ }^{12}$ but prevalence of depression in care home settings was unchanged, with approximately one in ten residents having case-level depression (CFAS I: $10.0 \%, 95 \%$ CI 6.1-16.1\%; CFAS II: 9.8\%, 95\% CI 5.9-15.8\%).

Within the three centres, individuals living in Newcastle were more likely to have case-level depression in CFAS I but less likely to be depressed in CFAS II (risk ratio Newcastle versus Cambridgeshire CFAS I: $3.21,95 \%$ CI $1.56-6.59, \quad P=0.002$; CFAS II $0.74,95 \%$ CI $0.58-0.94, P=0.027$; test for interaction, $P=0.0001$ ) (Table 2). Case-level depression was associated with living in a more deprived area in both studies. In CFAS I, the risk of depression was raised in all quartiles compared with the least deprived quartile $(P=0.018)$. In CFAS II, higher risk was observed in the most deprived quartile only $(P=0.0002)$.

The proportion of older people receiving antidepressant medication in CFAS II was more than double that in CFAS I (adjusted risk ratio $2.79,95 \%$ CI 1.96-3.97, $P<0.0001$ ). Estimated prevalence of antidepressant use from the CFAS I cohort was 4.2\% (95\% CI 2.9$6.1 \%$ ) and $10.7 \%$ (95\% CI 10.0-11.5\%) among CFAS II participants (Table 1). In CFAS II, after adjustment for other sociodemographics, women were more likely to be receiving antidepressant medication compared with men (risk ratio 2.05 , 95\% CI $1.76-$ $2.39, P<0.0001$ ) (Table 3 ). There was no evidence that the relationship between gender and receiving antidepressant medication had changed since CFAS I (test for interaction, $P=0.78$ ). As with the prevalence of case-level depression, there was no discernible age effect on antidepressant medication prescription. In care homes the use of antidepressants was nearly four times higher in CFAS II 
Table 1 Number with known depression status, depression prevalence and antidepressant treatment, by age, gender and residential status

\begin{tabular}{|c|c|c|c|c|c|c|}
\hline & \multicolumn{3}{|c|}{ CFAS I } & \multicolumn{3}{|c|}{ CFAS II } \\
\hline & $N^{\mathrm{a}}$ & $\begin{array}{l}\text { Depression, } \\
\%(95 \% \mathrm{Cl})\end{array}$ & $\begin{array}{l}\text { Antidepressant } \\
\text { medication, \% (95\% Cl) }\end{array}$ & $N$ & $\begin{array}{l}\text { Depression, } \\
\%(95 \% \mathrm{Cl})\end{array}$ & $\begin{array}{l}\text { Antidepressant } \\
\text { medication, \% ( } 95 \% \mathrm{Cl})\end{array}$ \\
\hline All & 1457 & $8.1(6.4-10.1)$ & $4.0(2.8-5.6)$ & 7723 & $6.7(6.1-7.3)$ & $10.7(10.0-11.4)$ \\
\hline Men & 531 & $6.3(4.2-9.4)$ & $2.9(1.5-5.4)$ & 3525 & $4.5(3.9-5.3)$ & $6.6(5.8-7.5)$ \\
\hline Women & 926 & $9.1(6.9-12.0)$ & $4.6(3.0-6.9)$ & 4198 & $8.3(7.5-9.2)$ & $13.9(12.8-15.1)$ \\
\hline 65-74 years & 630 & $7.1(5.2-9.7)$ & $4.5(2.8-7.2)$ & 3812 & $6.6(5.8-7.4)$ & $9.8(8.9-10.9)$ \\
\hline 75-84 years & 554 & $8.6(5.9-12.4)$ & $3.7(2.0-6.7)$ & 2900 & $7.0(6.1-8.0)$ & $11.4(10.2-12.6)$ \\
\hline$\geq 85$ years & 273 & $9.5(5.2-16.7)$ & $3.0(1.5-5.9)$ & 1011 & $6.1(4.7-7.8)$ & $11.6(9.7-13.8)$ \\
\hline \multicolumn{7}{|c|}{ Men in community } \\
\hline 65-74 years & 274 & $4.8(2.8-8.2)$ & $2.8(1.2-6.6)$ & 1859 & $4.3(3.5-5.4)$ & $6.2(5.1-7.4)$ \\
\hline 75-84 years & 166 & $8.5(4.1-16.7)$ & $3.2(1.0-9.2)$ & 1275 & $4.5(3.4-5.8)$ & $6.1(4.9-7.5)$ \\
\hline$\geq 85$ years & 40 & $4.6(1.3-15.3)$ & 0 & 337 & $4.9(3.1-7.8)$ & $7.9(5.3-11.5)$ \\
\hline Overall & 480 & $6.1(3.9-9.4)$ & $2.8(1.4-5.4)$ & 3471 & $4.5(3.8-5.2)$ & $6.3(5.5-7.2)$ \\
\hline \multicolumn{7}{|c|}{ Men in care homes } \\
\hline 65-74 years & 17 & $4.4(0.6-27.1)$ & $5.8(0.7-33.3)$ & 11 & $18.8(4.4-54.1)$ & $3.9(0.5-25.4)$ \\
\hline 75-84 years & 14 & $15.7(3.8-47.0)$ & $5.2(0.6-33.9)$ & 24 & $7.2(1.0-38.3)$ & $34.0(16.5-57.2)$ \\
\hline$\geq 85$ years & 18 & $13.4(3.0-43.8)$ & $9.0(1.2-44.8)$ & 19 & 0 & $19.3(6.6-44.7)$ \\
\hline Overall & 49 & $11.9(4.8-26.6)$ & $6.6(1.9-20.5)$ & 54 & $7.2(2.2-21.0)$ & $21.3(11.9-35.1)$ \\
\hline \multicolumn{7}{|c|}{ Women in community } \\
\hline 65-74 years & 329 & $9.0(6.0-13.4)$ & $5.9(3.2-10.5)$ & 1935 & $8.6(7.4-10.0)$ & $13.0(11.5-14.6)$ \\
\hline 75-84 years & 318 & $8.5(5.2-13.5)$ & $3.6(1.6-8.1)$ & 1563 & $8.5(7.2-10.0)$ & $14.4(12.7-16.3)$ \\
\hline$\geq 85$ years & 142 & $11.9(5.5-23.7)$ & $2.6(1.0-6.4)$ & 562 & $6.6(4.8-9.1)$ & $10.5(8.3-13.3)$ \\
\hline Overall & 789 & $9.1(6.8-12.2)$ & $4.4(2.8-6.9)$ & 4060 & $8.2(7.4-9.1)$ & $13.1(12.1-14.2)$ \\
\hline \multicolumn{7}{|c|}{ Women in care homes } \\
\hline 65-74 years & 9 & $39.8(13.7-73.3)$ & $10.3(1.4-48.6)$ & 7 & 0 & $69.3(29.2-92.5)$ \\
\hline $75-84$ years & 55 & $10.2(3.5-26.5)$ & $9.6(3.2-25.7)$ & 38 & $21.0(9.8-39.6)$ & $38.6(23.8-55.9)$ \\
\hline$\geq 85$ years & 70 & $6.0(2.4-14.4)$ & $6.1(1.8-19.1)$ & 93 & 7.9 (3.5-17.1) & $26.6(18.0-37.5)$ \\
\hline Overall & 134 & $9.4(5.1-16.7)$ & $7.6(3.5-15.9)$ & 138 & $10.7(6.0-18.2)$ & 31.9 (23.9-41.1) \\
\hline \multicolumn{7}{|c|}{ Total in community } \\
\hline 65-74 years & 603 & $7.0(5.0-9.6)$ & $4.4(2.7-7.2)$ & 3794 & $6.6(5.8-7.4)$ & $9.7(8.8-10.7)$ \\
\hline 75-84 years & 484 & $8.5(5.7-12.5)$ & $3.5(1.8-6.7)$ & 2838 & $6.7(5.9-7.7)$ & $10.8(9.6-12.0)$ \\
\hline$\geq 85$ years & 182 & $10.2(5.0-19.6)$ & $2.0(0.8-5.0)$ & 899 & $6.0(4.6-7.8)$ & $9.6(7.8-11.7)$ \\
\hline Overall & 1269 & $8.0(6.2-10.1)$ & $3.8(2.6-5.5)$ & 7531 & $6.5(6.0-7.1)$ & $10.1(9.4-10.8)$ \\
\hline \multicolumn{7}{|c|}{ Total in care homes } \\
\hline 65-74 years & 26 & $17.7(6.6-39.6)$ & $7.5(1.8-25.8)$ & 18 & $11.3(2.7-37.1)$ & $30.3(11.0-60.3)$ \\
\hline 75-84 years & 69 & 11.7 (5.2-24.3) & $8.5(3.1-21.0)$ & 62 & $16.2(7.9-30.2)$ & $37.0(25.1-50.7)$ \\
\hline$\geq 85$ years & 88 & $7.2(3.3-15.0)$ & $6.6(2.2-17.5)$ & 112 & 6.7 (2.9-14.6) & $25.5(17.7-35.2)$ \\
\hline Overall & 183 & $10.0(6.1-16.1)$ & $7.4(3.8-13.8)$ & 192 & $9.8(5.9-15.8)$ & $29.2(22.6-36.7)$ \\
\hline \multicolumn{7}{|c|}{ By gender, standardised to 2011 age structure } \\
\hline Men & & $5.9(3.9-8.8)$ & $3.1(1.6-5.9)$ & & $4.5(3.8-5.3)$ & $6.4(5.9-7.3)$ \\
\hline Women & & $9.1(6.9-11.9)$ & $4.9(3.1-7.6)$ & & $8.5(7.7-9.5)$ & $13.8(12.7-15.0)$ \\
\hline Total & & $7.9(6.3-9.9)$ & $4.2(2.9-6.1)$ & & $6.8(6.3-7.5)$ & $10.7(10.0-11.5)$ \\
\hline
\end{tabular}

(29.2\%, 95\% CI $22.6-36.7 \%)$ than CFAS I $(7.4 \%, 95 \%$ CI $3.8-$ $13.8 \%)$. However, after adjustment for sociodemographic factors, the increased risk of receiving antidepressants for care home residence was similar to that of older people living in their own homes (CFAS I: risk ratio 3.07, 95\% CI 1.47-6.42, $P=0.0029$; CFAS II: risk ratio $2.76,95 \% \mathrm{CI} 2.12-3.61, P<0.0001$; test for interaction, $P=0.79$ ), an indication of the change in the care home population.

There was relatively little overlap between those who were receiving antidepressant medications and those reaching caselevel diagnosis of depression at time of interview in either CFAS I or in CFAS II (Fig. 1, Supplementary Table 2). In CFAS I, 1.3\% had study diagnostic-level depression and were receiving antidepressants, over 1 in 20 (6.8\%) met study diagnostic level of depression but were not receiving antidepressants and a further $2.7 \%$ were receiving antidepressant medication but did not meet study diagnosis of depression. The equivalent proportions in CFAS II were $1.9 \%$, $4.7 \%$ and $8.8 \%$, respectively. In both cohorts, most people with caselevel depression were not receiving antidepressant treatment and most of those receiving antidepressants did not have a study diagnosis of depression at time of interview.

\section{Discussion}

From CFAS II we estimate that the prevalence of case-level depression is $6.8 \%$ in people aged $\geq 65$ years. This was a relative but not statistically significant decrease of around $20 \%$ since CFAS I, conducted two decades earlier, after allowing for changes in age structure and other demographic differences. There was a threefold increase in antidepressant use over the same time period. Among CFAS I and CFAS II participants, only a minority of those with case-level depression were receiving antidepressant medications, and in both studies, most of those taking antidepressants did not have depression, with this proportion of the population increasing dramatically in CFAS II.

\section{Strengths and limitations}

The analysis presented here is based on samples drawn from population-representative primary care registers that include residents of care homes, use diagnostic criteria held constant between two time points and are of sufficient scale to estimate prevalence. The approach that we used, direct interview by rigorously trained 
Table 2 Adjusted ${ }^{\mathrm{a}}$ risk ratios for sociodemographic factors and depression, CFAS I and CFAS II

\begin{tabular}{|c|c|c|c|c|c|}
\hline & $\begin{array}{l}\text { CFAS I risk } \\
\text { ratio }(95 \% \mathrm{Cl})\end{array}$ & $P$-value & $\begin{array}{l}\text { CFAS II risk } \\
\text { ratio }(95 \% \mathrm{Cl})\end{array}$ & $P$-value & $\begin{array}{l}\text { Test for interaction } \\
\text { (CFAS I and CFAS II) } P \text {-value }\end{array}$ \\
\hline \multicolumn{6}{|l|}{ Gender } \\
\hline Male & Ref & \multirow[t]{2}{*}{0.40} & Ref & \multirow[t]{2}{*}{$<0.0001$} & \multirow[t]{2}{*}{0.16} \\
\hline Female & $1.25(0.74-2.11)$ & & $1.87(1.55-2.26)$ & & \\
\hline \multicolumn{6}{|l|}{ Age group } \\
\hline 65-74 years & Ref & \multirow[t]{3}{*}{0.78} & Ref & \multirow[t]{3}{*}{0.23} & \multirow[t]{3}{*}{0.44} \\
\hline $75-84$ years & $1.06(0.64-1.76)$ & & $1.02(0.85-1.26)$ & & \\
\hline$\geq 85$ years & $1.30(0.62-2.72)$ & & $0.79(0.59-1.06)$ & & \\
\hline \multicolumn{6}{|l|}{ Residence } \\
\hline Community & Ref & \multirow[t]{2}{*}{0.74} & Ref & \multirow[t]{2}{*}{0.12} & \multirow[t]{2}{*}{0.47} \\
\hline Care home & $1.12(0.59-2.13)$ & & $1.51(0.89-2.57)$ & & \\
\hline \multicolumn{6}{|l|}{ Centre } \\
\hline Cambridgeshire & Ref & \multirow[t]{3}{*}{0.0022} & Ref & \multirow[t]{3}{*}{0.027} & \multirow[t]{3}{*}{0.0001} \\
\hline Newcastle & $3.21(1.56-6.59)$ & & $0.74(0.58-0.94)$ & & \\
\hline Nottingham & $1.80(0.84-3.84)$ & & $0.94(0.76-1.17)$ & & \\
\hline \multicolumn{6}{|c|}{ Townsend deprivation index (quartiles) } \\
\hline Q1 (least deprived) & Ref & \multirow[t]{4}{*}{0.018} & Ref & \multirow[t]{4}{*}{0.0002} & \multirow[t]{4}{*}{0.0096} \\
\hline Q2 & $2.18(1.06-4.49)$ & & $0.89(0.69-1.13)$ & & \\
\hline Q3 & $3.07(1.51-6.25)$ & & $1.04(0.82-1.33)$ & & \\
\hline Q4 (most deprived) & $2.27(1.08-4.75)$ & & $1.56(1.22-2.00)$ & & \\
\hline
\end{tabular}

interviewers across sites, with standardised detailed questioning by validated methods, should ensure that our detection of depression is comparable across time. In drawing conclusions from our findings, the methodological limitations need to be considered. In spite of identical recruitment approaches, non-response in CFAS II was greater than in that achieved in CFAS I two decades earlier. However, the risk to biased estimates owing to lack of representativeness is limited by back-weighting of factors associated with non-response. Our measures of medication are based on what is reported as taken rather than what is prescribed, and it is not possible to determine the appropriateness or otherwise of antidepressant prescribing for study participants. Among older people, the level of non-adherence to medication ${ }^{16}$ presents challenges for studies based on prescription data.

The two-stage design (screening and assessment) of CFAS I limits the number of participants with diagnostic assessment, meaning the power to detect associations was greater at CFAS II. The analyses we report here are cross-sectional for each cohort, which limits our ability to comment on changes in duration of depressive or treatment episode. Both in the $\mathrm{UK}^{17}$ and elsewhere, ${ }^{18}$ psychological therapies are more widely used than at the time of CFAS I, but we did not ask participants about this directly and so cannot include non-medication treatment in our analysis.

\section{Findings in the context of the literature}

CFAS I and CFAS II have allowed for direct comparison of changes in prevalence and treatment of depression among people aged $\geq 65$ years across two decades. Prevalence estimates of depression are higher if samples are drawn from primary care attenders ${ }^{19}$ or where measurement is restricted to symptom scales. ${ }^{20}$ Our estimated prevalence of late-life depression from CFAS II is consistent with two reviews of epidemiological studies of comparable age groups. In the first,

\begin{tabular}{|c|c|c|c|c|c|}
\hline & $\begin{array}{l}\text { CFAS I risk } \\
\text { ratio }(95 \% \mathrm{Cl})\end{array}$ & $P$-value & $\begin{array}{l}\text { CFAS II risk } \\
\text { ratio }(95 \% \mathrm{Cl})\end{array}$ & $P$-value & $\begin{array}{l}\text { Test for interaction (CFAS I } \\
\text { and CFAS II) } P \text {-value }\end{array}$ \\
\hline \multicolumn{6}{|l|}{ Gender } \\
\hline Male & Ref & 0.15 & Ref & $<0.0001$ & 0.78 \\
\hline Female & $1.83(0.81-4.11)$ & & $2.05(1.76-2.39)$ & & \\
\hline \multicolumn{6}{|l|}{ Age group } \\
\hline 65-74 years & Ref & 0.24 & Ref & 0.047 & 0.46 \\
\hline 75-84 years & $0.76(0.34-1.69)$ & & $1.08(0.93-1.25)$ & & \\
\hline$\geq 85$ years & $0.47(0.19-1.13)$ & & $0.82(0.65-1.02)$ & & \\
\hline \multicolumn{6}{|l|}{ Residence } \\
\hline Community & Ref & 0.0029 & Ref & $<0.0001$ & 0.79 \\
\hline Care home & $3.07(1.47-6.42)$ & & $2.76(2.12-3.61)$ & & \\
\hline \multicolumn{6}{|l|}{ Centre } \\
\hline Cambridgeshire & Ref & 0.34 & Ref & $<0.0001$ & 0.93 \\
\hline Newcastle & $0.93(0.37-2.36)$ & & $1.01(0.84-1.20)$ & & \\
\hline Nottingham & $0.58(0.24-1.36)$ & & $0.68(0.56-0.82)$ & & \\
\hline \multicolumn{6}{|c|}{ Townsend deprivation index (quartiles) } \\
\hline Q1 (least deprived) & Ref & 0.13 & Ref & 0.029 & 0.10 \\
\hline Q2 & $2.23(0.87-5.75)$ & & $0.86(0.71-1.05)$ & & \\
\hline Q3 & $0.85(0.33-2.17)$ & & $0.95(0.78-1.14)$ & & \\
\hline Q4 (most deprived) & $1.60(0.57-4.49)$ & & $1.19(0.98-1.44)$ & & \\
\hline
\end{tabular}


Men

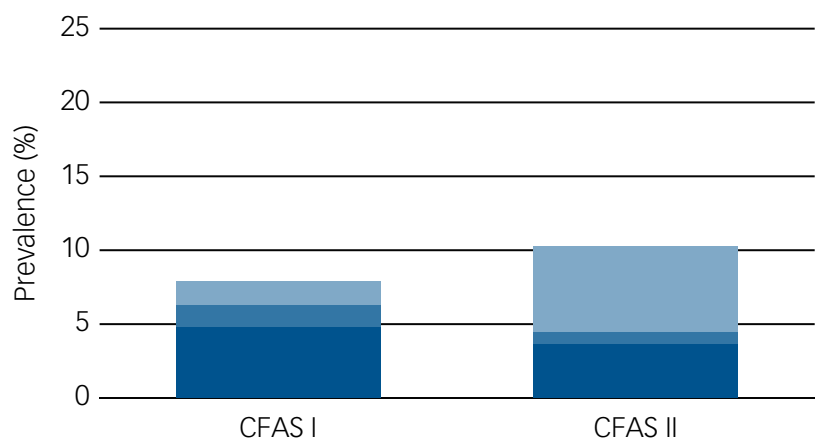

Women

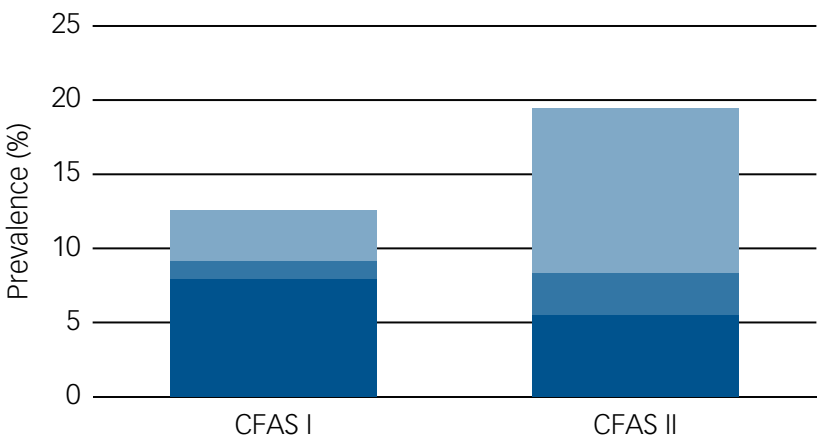

- Depressed, no antidepressants

- Depressed, antidepressants

- Not depressed, antidepressants

Fig. 1 Prevalence of depression and antidepressant treatment by gender, CFAS I and CFAS II.

CFAS, Cognitive Function and Ageing Studies.

estimates of major depression according to ICD-10 or DSM-IV criteria ranged from 0.9 to $9.4 \%$, with variation likely owing to the methodological and contextual differences of the reviewed studies. ${ }^{21}$ In the second, pooled prevalence from 13 studies was $7.2 \%{ }^{3}$

Prevalence of case-level depression decreased from $7.9 \%$ in CFAS I to $6.8 \%$ in CFAS II, but after adjustment this change was not statistically significant. Although other studies have looked at depression across time with the same methodology, ${ }^{22-24}$ their focus has been on younger age groups, making direct comparison difficult. A relatively short-term comparison from a repeat population interview survey between 1998 and 2004 of Australian adults of all ages found no change in prevalence of depression. ${ }^{25}$ Analyses of general practice attenders, where prevalence estimates will be higher than those from population studies, found that the incidence decreased from 22.5 to 14.0 per 1000 person-years between 1996 and 2006, and this decline was greater among those aged $\geq 65$ years. ${ }^{26}$ In our analysis there was evidence of a change over time in the association between depression and living in a deprived area. That the risk appears to be confined to those in the most deprived quartile is perhaps indicative of changing social structures in England, with a decreasing proportion of the population being socioeconomically classified as 'working class'. ${ }^{27}$

Taking antidepressant medication increased from 4.0 to $10.7 \%$ over the 20-year period. This is similar to the rise reported by others over a similar time period. ${ }^{8-10}$ Depression can be effectively treated by medication; therefore it is expected that there will be a substantial proportion of people taking medication, but not reporting the symptoms of depression. In CFAS I the number of those with untreated case-level depression was over twice that of those receiving antidepressant medication without a diagnosis. These proportions were reversed in CFAS II. There are a number of possible explanations for this apparent mismatch between prevalence and treatment, although the observational study design precludes any inference of a causal relationship. For those untreated, we cannot say if this is because of treatment not being offered, not being accepted, having been unsuccessful in the past or whether other, non-pharmacological treatments were being received. Participants who were not identified as depressed but were receiving antidepressant medications may have been treated successfully in the past and continue to take medications, perhaps preventing a rise in depression prevalence that might have been observed otherwise. Antidepressants may be more likely to be used to treat depression that does not reach the case-level threshold used in this study. Authors from other epidemiological studies have suggested that the need for treatment is poorly matched with provision. ${ }^{28}$
It is unclear whether observed increases in treatment are a reflection of overdiagnosis, better recognition and prescribing, or the prescribing of antidepressant medication for conditions other than depression. The comparisons made here were during a time of change in the way depression is detected and treated. In England, where most older people with depression are managed in primary care settings, policy shifts have been toward greater surveillance of those with chronic diseases. Depression directly affects 1 in 15 people aged $\geq 65$ years, with its effects felt by families and friends. Over two decades, substantial increases in access to antidepressant medication do not appear to be associated with change in prevalence of late-life depression. The natural history of treated and untreated depression, particularly for older people, remains poorly understood.

Antony Arthur (D), PhD, Professor of Nursing Science, School of Health Sciences,

Antony Arthur $\mathbb{D}_{\text {, PhD, Professor of Nursing Science, School of Health Sciences, }}$ University of East Anglia, UK; George M. Savva, PhD, Statistician, Core Science

Resources, Quadram Institute Biosciences, UK; Linda E. Barnes, RGN, CFAS National Co-ordinator, Department of Public Health and Primary Care, University of Cambridge, UK; Ayda Borjian-Boroojeny, Medical Student, Norwich Medical School, University of East Anglia, UK; Tom Dening, MD, Professor of Dementia Research, School of Medicine, University of Nottingham, UK; Carol Jagger, PhD, Professor of Epidemiology and Ageing, Institute for Health and Society, Newcastle University, UK; Fiona E. Matthews (D), PhD, Professor of Epidemiology, Newcastle University; and University of Cambridge, UK; Louise Robinson, MD, Professor of Primary Care and Ageing, Institute for Health and Society, Newcastle University, UK; Carol Brayne, MD, Professor of Public Health Medicine, Department of Public Health and Primary Care, University of Cambridge, UK; and the Cognitive Function and Ageing Studies Collaboration, see Acknowledgements

Correspondence: Antony Arthur, School of Health Sciences, University of East Anglia, Norwich Research Park, Norwich NR4 7TJ, UK. Email: antony.arthur@uea.ac.uk

First received 30 Oct 2018, final revision 2 Jul 2019, accepted 30 Jul 2019

\section{Supplementary material}

Supplementary material is available online at https://doi.org/10.1192/bjp.2019.193.

\section{Funding}

CFAS I was funded by the Medical Research Council (research grant G9901400) and the UK Department of Health. CFAS II was funded by the Medical Research Council (research grant G0601022) and the Alzheimer's Society (grant 294); additional support was provided from the National Institute for Health Research's Clinical Research Network in West Anglia and Trent, and the Dementias and Neurodegenerative Disease Research Network in Newcastle.

\section{Acknowledgements}

We thank participants, their families, general practitioners and their staff, and primary care trusts for their cooperation and support. We thank the CFAS fieldwork interviewers at 
Cambridge, Nottingham and Newcastle (UK), and the CFAS core data management team at Cambridge.

Members of the CFAS Cambridge core team and fieldwork support: $E$ Green, $L$ Gao and R. Barnes. CFAS management committee members: A. Arthur, C. Baldwin, L.E. Barnes, C. Brayne, A. Comas-Herrera, T. Dening, G. Forster, S. Harrison, P.G. Ince, C. Jagger, F.E. Matthews, I.G. McKeith, B. Parry, J. Pickett, L. Robinson, B.C.M. Stephan, S. Wharton, R. Wittenberg and B. Woods. CFAS biological resource advisory committee members: R. Weller (Chair).

\section{References}

1 World Health Organization (WHO). Depression. WHO, 2017 (http://www.who. int/mediacentre/factsheets/fs369/en/).

2 Wetherell JL, Petkus AJ, Mcchesney K, Stein MB, Judd PH, Rockwell E, et al. Older adults are less accurate than younger adults at identifying symptoms of anxiety and depression. J Nerv Ment Dis 2009; 197(8): 623-6.

3 Luppa M, Sikorski C, Luck T, Ehreke L, Konnopka A, Wiese B, et al. Age- and gender-specific prevalence of depression in latest-life: systematic review and meta-analysis. J Affect Disord 2012; 136(3): 212-21.

4 Mojtabai R, Olfson M. Major depression in community-dwelling middle-aged and older adults: prevalence and 2- and 4-year follow-up symptoms. Psychol Med 2004; 34(4): 623-34.

5 Scott KM, Von Korff M, Alonso J, Angermeyer M, Bromet EJ, Bruffaerts R, et al. Age patterns in the prevalence of DSM-IV depressive/anxiety disorders with and without physical co-morbidity. Psychol Med 2008; 38(11): 1659-69.

6 Snowdon J, Draper B, Brodaty H, Ames D, Chiu E. Prevalence and treatment of late life depression. Aust N Z J Psychiatry 2010; 44(11): 1054.

7 Hillhouse TM, Porter JH. A brief history of the development of antidepressant drugs: from monoamines to glutamate. Exp Clin Psychopharmacol 2015; 23(1): $1-21$.

8 Office for National Statistics (ONS). Social Trends 41: Health. ONS, 2011 (https://webarchive.nationalarchives.gov.uk/20151014074225/http://www. ons.gov.uk/ons/rel/social-trends-rd/social-trends/social-trends-41/health. pdf).

9 Olfson M, Marcus SC. National patterns in antidepressant medication treatment. Arch Gen Psychiatry 2009; 66(8): 848-56.

10 Aarts N, Noordam R, Hofman A, Tiemeier H, Stricker BH, Visser LE. Utilization patterns of antidepressants between 1991 and 2011 in a population-based cohort of middle-aged and elderly. Eur Psychiatry 2014; 29(6): 365-70.

11 Gao L, Green E, Barnes LE, Brayne C, Matthews FE, Robinson L, et al. Changing non-participation in epidemiological studies of older people: evidence from the Cognitive Function and Ageing Study I and II. Age Ageing 2015; 44(5): 867-73.

12 Matthews FE, Arthur A, Barnes LE, Bond J, Jagger C, Robinson L, et al. A twodecade comparison of prevalence of dementia in individuals aged 65 years and older from three geographical areas of England: results of the Cognitive Function and Ageing Study I and II. Lancet 2013; 382(9902): 1405-12.

13 Copeland JR, Dewey ME, Griffiths-Jones HM. A computerized psychiatric diagnostic system and case nomenclature for elderly subjects: GMS and AGECAT. Psychol Med 1986; 16(1): 89-99.
14 British Medical Association \& Royal Pharmaceutical Society of Great Britain British National Formulary (March 2015, Issue 69). BMJ Books and Pharmaceutical Press, 2015.

15 Townsend P, Phillimore P, Beattie A. Health and Deprivation: Inequality and the North. Croom Helm, 1988.

16 Zelko E, Klemenc-Ketis Z, Tusek-Bunc K. Medication adherence in elderly with polypharmacy living at home: a systematic review of existing studies. Mater Sociomed 2016; 28(2): 129-32.

17 Health and Social Care Information Centre. Psychological Therapies, England: Annual Report on the Use of Improving Access to Psychological Therapies Services - 2012-13. Health and Social Care Information Centre, part of the Government Statistical Service, 2014 (https://files.digital.nhs.uk/publicationimport/pub13xxx/pub13339/psyc-ther-ann-rep-2012-13.pdf).

18 Goldney RD, Fisher LJ, Grande ED, Taylor AW, Hawthorne G. Have education and publicity about depression made a difference? Comparison of prevalence, service use and excess costs in South Australia: 1998 and 2004. Aust N Z J Psychiatry 2007; 41(1): 38-53.

19 Licht-Strunk E, van der Kooij KG, van Schaik DJ, van Marwijk HW, van Hout HP, de Haan $\mathrm{M}$, et al. Prevalence of depression in older patients consulting their general practitioner in The Netherlands. Int J Geriatr Psychiatry 2005; 20(11): 1013-9.

20 Solhaug HI, Romuld EB, Romild U, Stordal E. Increased prevalence of depression in cohorts of the elderly: an 11-year follow-up in the general population the HUNT study. Int Psychogeriatr 2012; 24(1): 151-8.

21 Djernes JK. Prevalence and predictors of depression in populations of elderly: a review. Acta Psychiatr Scand 2006; 113(5): 372-87.

22 de Graaf R, ten Have M, van Gool C, van Dorsselaer S. Prevalence of mental disorders and trends from 1996 to 2009. Results from the Netherlands Mental Health Survey and Incidence Study-2. Soc Psychiatry Psychiatr Epidemiol 2012; 47(2): 203-13.

23 Spiers N, Brugha TS, Bebbington P, McManus S, Jenkins R, Meltzer H. Age and birth cohort differences in depression in repeated cross-sectional surveys in England: the National Psychiatric Morbidity Surveys, 1993 to 2007. Psychol Med 2012; 42(10): 2047-55.

24 Jeuring HW, Comijs HC, Deeg DJH, Stek ML, Huisman M, Beekman ATF. Secular trends in the prevalence of major and subthreshold depression among 55-64year olds over 20 years. Psychol Med 2018; 48(11): 1824-34.

25 Hawthorne G, Goldney R, Taylor AW. Depression prevalence: is it really increasing? Aust N Z J Psychiatry 2008; 42(7): 606-16.

26 Rait G, Walters K, Griffin M, Buszewicz M, Petersen I, Nazareth I. Recent trends in the incidence of recorded depression in primary care. Br J Psychiatry 2009; 195(6): 520-4.

27 Goldthorpe JH. Social class mobility in modern Britain: changing structure, constant process. J Brit Acad 2016; 4: 89-111.

28 Mojtabai R, Jorm AF. Trends in psychological distress, depressive episodes and mental health treatment-seeking in the United States: 2001-2012. J Affect Disord 2015; 174: 556-61. 